\title{
Joint Ultrasonography of Goats Infected by the Caprine Arthritis Encephalitis Virus
}

\author{
Laecio da Silva Moura', Gerson Tavares Pessoa', Francisco das Chagas Araújo Sousa', \\ Rayssa Dourado Fontenele ${ }^{2}$, Marina Pinto Sanches ${ }^{2}$, Renan Paraguassu de Sá Rodrigues ${ }^{2}$, \\ Luciana Rodrigues Alves ${ }^{2}$, Jefferson Rodrigues Araújo ${ }^{3}$, Larisse Danielle Silva Freire ${ }^{3}$, \\ Jacyara de Jesus Pereira Alves ${ }^{4} \&$ Flávio Ribeiro Alves ${ }^{5}$
}

\begin{abstract}
Background: The most important form of caprine arthritis encephalitis virus in the goat is the arthritic, generally observed in animals over eight months of age. Differently in sheep, there is less arthritis incidence, affecting 2-3-year-old animals. The clinical alterations frequently affect goat joints, and an increase in the joint consistency and size is observed. The objective of the present study was to standardize the ultrasound technique to access joints in animals infected with the caprine arthritis encephalitis virus (CAEV), so that it can be a complimentary support tool for diagnosis and animal management. Materials, Methods \& Results: Animals were examined from farms located in the municipality of Teresina, state of Piauí, Brazil. For this, the M-Turbo, Sonosite Fujifilm ultrasonography apparatus was used, attached to a linear transducer with 10-13 MHz frequency. The ultrasound examination analyzed three regions: patella-humerus joint, carpal and tarsal joints. The patella-humerus joint was characterized by its concave convex surface. The surface of the head humerus was a fine hyperechoic line composed by the junction between the joint cartilage and the subcontinent bone. The sub patella muscle was visible and its fibers present a parallel and hypoechogenic pattern compared to bone tissue. A discreet muscle edge with echogenicity was observed separating the sub patella and supraspinatus muscles. The surface of the proximal and distal rows of the carpal bones was characterized by fine hyperechogenic lines that formed acoustic shadow. Regarding the bones of the tarsal joint, the surface of the central tarsal joint bone was observed centrally as a fine, hyperechogenic line. The third tarsal joint bone was visualized on the left side and was represented by a thick hyperechoic line, while the fourth tarsal joint bone was observed to the right with a hypoechogenic surface and both formed acoustic shadow.

Discussion: Joint inflammation caused by other diseases, such as derived from bacteria of the Micoplasma genus can suggest similar semiological aspects and can present positive results for the joint clinical index. Studies carried out have established measurements of the joints of animals affected by various degrees of arthritis, where absolute values equal or less than $5.5 \mathrm{~cm}$ would be indicative of negative arthritis diagnosis, variations between 6.0 and $6.5 \mathrm{~cm}$ would be considered suspicious and when equal or greater than $7.0 \mathrm{~cm}$ they would be positive. From the anatomical point of view, ultrasound assessment of the joints of the normal animals showed a morphological pattern as observed in dogs, horses and humans. The loss of echogenicity, surface erosions and exposure of subchondral bone observed in goats infected with CAEV were also reported in dogs with patella-humerus osteochondrosis, by the presence of a cartilage flap seen radiographically, or even as cracks, characterized by a hyperechoic line parallel to the subchondral defect, in the ultrasonography examination. The lesions observed in the ultrasound examination showed various degrees of osteoarthritis, with the presence of sound hyperreflection, hyperechogenic areas, cartilage lesions with erosion of the subchondral bone and loss of anatomic limits, and these characteristics were described for the metacarpal phalangeal and metatarsal phalangeal joints of dogs submitted to routine radiographic examination. The ultrasound examination of the joints of normal goats and goats infected with caprine arthritis encephalitis virus allowed the comparative description of normal anatomy, evolution of joint and adjacent soft tissue lesions, generating valuable clinical and surgical information.
\end{abstract}

Keywords: arthritis, common inflammatory disease, lentivirus, ultrasonography, ruminants.

${ }^{1}$ Animal Science Post-Graduate Program, Federal University of Piauí (UFPI), Teresina, PI, Brazil. ${ }^{2}$ Undergraduate Student of Veterinary Medicine, UFPI, Teresina. ${ }^{3}$ Residency Program in Diagnostic Imaging in Veterinary Medicine, UFPI, Teresina. ${ }^{4}$ University Hospital, Department of Surgery, UFPI, Teresina. ${ }^{5}$ Department of Veterinary Morphophysiology, UFPI, Teresina. CORRESPONDENCE: F.R. Alves [flavioribeiro@ ufpi.edu.br - Tel.: +55 (86) 3215-5757]. Departamento de Morfofisiologia Veterinária, Centro de Ciências Agrárias, Universidade Federal do Piauí, UFPI, Campus da Socopo. CEP 64049-550 Teresina, PI, Brazil. 


\section{INTRODUCTION}

Raising goats in the north-east of Brazil is hindered by innumerable diseases that affect the health of the herd [11]. One of the diseases is caprine arthritis encephalitis (CAE) an infection caused by the caprine arthritis encephalitis virus (CAEV). This lentivirus can cause persistent infection throughout life, resulting in subclinical inflammation in one or more tissues and organs, such as joints, the brain, lungs and mammary glands [5].

Ultrasound is a consolidated examination sensitive to observation of alterations in the periarticular soft tissues [25], joint surfaces and can also give early diagnosis of morphological modifications caused by osteoarthritis (OA). This information can be proved by the changes that occur in the synovial membrane, joint capsule and increase in the periarticular volume [8].

Lesions produced by this infection are similar to those observed in rheumatoid arthritis seen in humans, characterizing these animals as potential models for the study of this disease [13]. In this context, the present study, a CAEV-infected goat model, endeavored to standardize the technique for ultrasound access to joints of animals affected by CAEV, so that this can be a complimentary support tool to diagnosis and animal management.

\section{MATERIALS AND METHODS}

\section{Animals}

Twenty one to two-year-old crossbred goats were used, from farms located in the municipality of Teresina, Piauí state, Brazil. The animals were divided into two groups of 10 animals each. The first group consisted of animals infected with CAEV (CAEV group) and the second group consisted of animals negative to CAEV (Control Group). The animals were assessed serologically before the experimental design using the agarose gel immunodiffusion test (IDGA) ${ }^{1}$ [32]. The test showed that the animals were selected because they were negative.

The methodology of this study was approved by the Committee of Ethics and Animal Experimentation (Comitê de Ética e Experimentação Animal CEEA) of the Federal University of Piauí, registration number $\mathrm{N}^{\circ} 10 / 09$.

\section{Ultrasound examination}

The Control and CAEV Groups were submitted to ultrasound examination in three specific regions: the patella-humerus joint (PHJ), carpal and tarsal joints. The ultrasonographic images were analyzed by a radiologist veterinary physician, in a blind study.

For this, an M-Turbo, Sonosite Fujifilm² ultrasound equipment was used attached to a linear 10-12 $\mathrm{MHz}$ multifrequency transducer. Access to the joints was made on the dorsolateral surface for the patella-humerus joint and dorsolateral and medial surfaces for the carpal and tarsal joints, after shaving the fur, to obtain an adequate acoustic window and the minimal possible artefact. After infection by CAEV was confirmed, the positive group was assessed at three different times: $0,15^{\text {th }}$ and $45^{\text {th }}$ day.

\section{Statistical analysis}

The data was submitted to the normality distribution test (Shapiro-Wilk and Kolmogorov-Smirnov) and later the means of the CAE positive and control groups were analyzed by the student $t$-test, with a confidence interval of $5 \%(P<0.5)$.

\section{RESULTS}

All the animals in the study were assessed by ultrasound that was shown to be an efficacious technique to assess the joints of goats native to the state of Piauí naturally infected by the caprine arthritis encephalitis virus. The values found using the joint clinical index were confirmed by the agarose gel immunodiffusion exam (IDGA), as shown in the values in Table 1. When difference was observed between the means of the two groups by the student $t$-test, statistical difference was observed between the means ( $t$ crítico $=1.73, P=2.07$ ).

Table 1. Results of the values regarding the clinical joint index in goat positive and negative to the caprine arthritis encephalitis virus.

\begin{tabular}{ccc}
\hline \multirow{2}{*}{ Animal } & \multicolumn{2}{c}{ Clinical Joint Index } \\
\cline { 2 - 3 } & CAEV Negative & CAEV Positive \\
\hline 01 & 5.2 & 7.2 \\
02 & 5.1 & 7.0 \\
03 & 4.8 & 7.3 \\
04 & 4.6 & 6.8 \\
05 & 4.9 & 6.9 \\
06 & 5.1 & 6.6 \\
07 & 5.3 & 7.1 \\
08 & 4.7 & 7.4 \\
09 & 4.6 & 7.3 \\
10 & 5.0 & 7.2 \\
Média & 4.93 & 7.08
\end{tabular}

Reference values [10]: ICA: $\leq 5.5$ - Animal negative; Between 6.0 and 6.5: clinically suspect animal; $\geq 7.0$ : Animal clinically ill. 
The normal joints were easily accessed so that the ultrasound examination could be made. A small quantity of synovial fluid was observed, but the contrasts between the joint cavity and the hyperechoic surface of the bones allowed assessment of this tissue for the occurrence of local pathological processes (Figure 1).

The patella-humerus joint was assessed from the dorsolateral face and was characterized by concave-convex surface (glenoid cavity of the patella versus humerus head). The humerus head surface was presented as a fine hyperechoic line composed of the junction between the joint cartilage and the subchondral bone. When examined by ultrasound the sub patellar muscle was visible and its fibers presented a parallel and hyperechoic pattern, compared to the bone tissue. A discreet muscular margin of medium echogenicity was observed separating the sub-patellar and supraspinatus muscles; the latter showed echogenicity similar to the sub-patellar (Figure 1A).

Dorsal access was adopted for the carpal, on the cranial surface of the joint, that enabled the visualization of the proximal and distal row of the carpal bones and the individualization of each bone. The proximal and distal row surface was characterized by thin hyperechoic lines forming acoustic shadow (Figure 1B).

The tarsal joint was accessed dorsolaterally and medially with the transducer perpendicular to the joint, in a frontal cut on the tarsal joint. The surface of the central tarsal joint was observed centrally as a fine and hyperechogenic line. The third tarsal bone joint was seen to the left represented by a thick hyperechoic line while the fourth tarsal bone joint was observed to the right with a hypoechogenic surface, both forming acoustic shadow (Figure 1C).

Access to joints of the CAE positive animals was more difficult. Generally all the articulations had advanced levels of arthrosis, characterized by decreased joint space and loss of the limits between the component bones of the joints (Figure 2).

The patella-humerus joint was characterized by increase in echogenicity associated to surface irregularities and exposure of the subchondral bone. Accumulated liquid in the tissues, due to the inflammatory process, caused loss of echogenicity of the sub patellar muscle and the limit margin with the supraspinatus muscle (Figure 2A). In addition, disorganization was identified in the fibers of the supraspinatus muscle, a characteristic of animals with tenosynovitis. The carpus became inaccessible, and there was total reflection in the sound beams, culminating in the formation of a large posterior acoustic shadow. The arthritis levels caused loss of the discrimination of each row and the precise definition of each bone (Figure 2B). The tarsal joint bones became indistinguishable anatomically. This draws attention to the lack of joint space, joint hyperechogenicity and probable establishment of pseudarthrosis (Figure 2C).
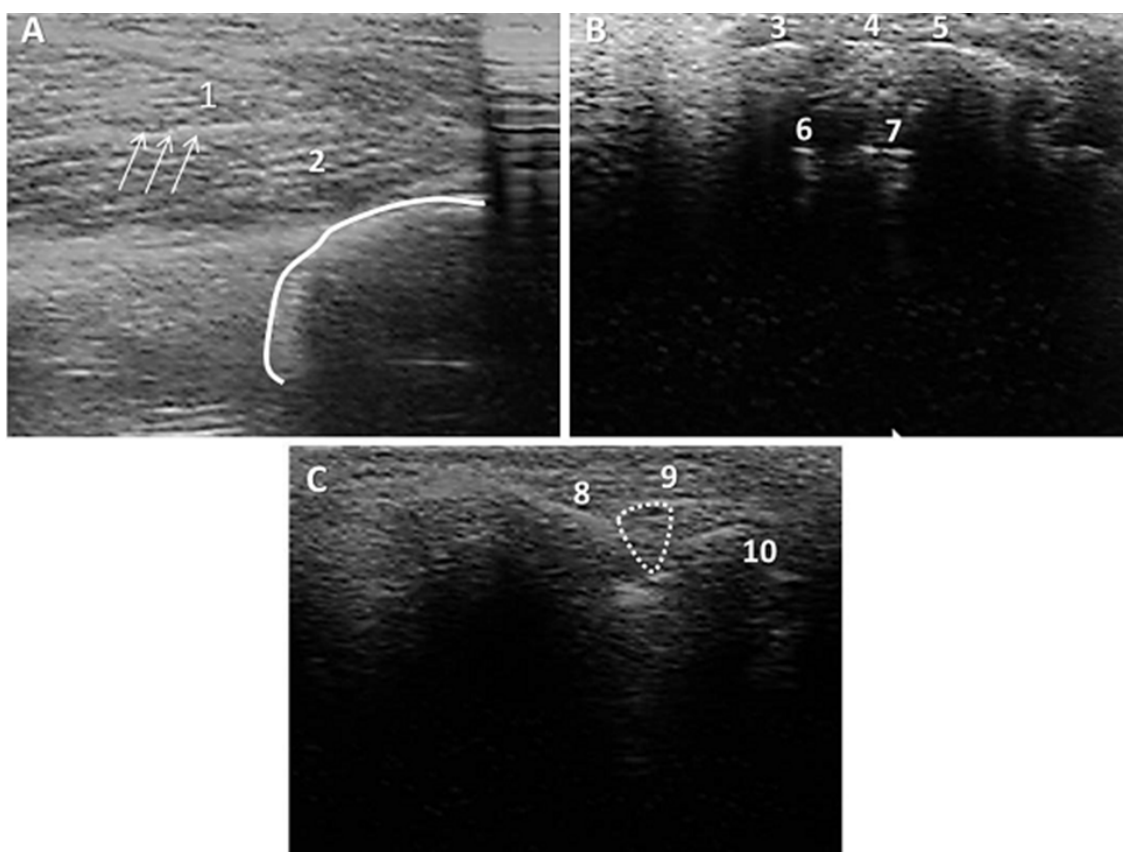

Figure 1. Ultrasound image of normal joints of goats native to the state of Piauí, Brazil. (A) surface of the humerus head. Echogenicity formed by the junction of the joint cartilage and the subchondral bone (line). (1) Sub patella muscle; (2) supraspinatus muscle. Note the muscle margin separating these muscles (arrows). (B) surface of the proximal and distal rows of the carpus. (3) Ulnar carpus bone; (4) intermediate carpus; (5) radial carpus; (6) IV carpal bone (7) II and III fused carpal bones. (C) tarsal joint. (8) III tarsal joint bone; (9) Central tarsal joint bone; 10) IV tarsal joint bone. Joint cavity (dotted line). 

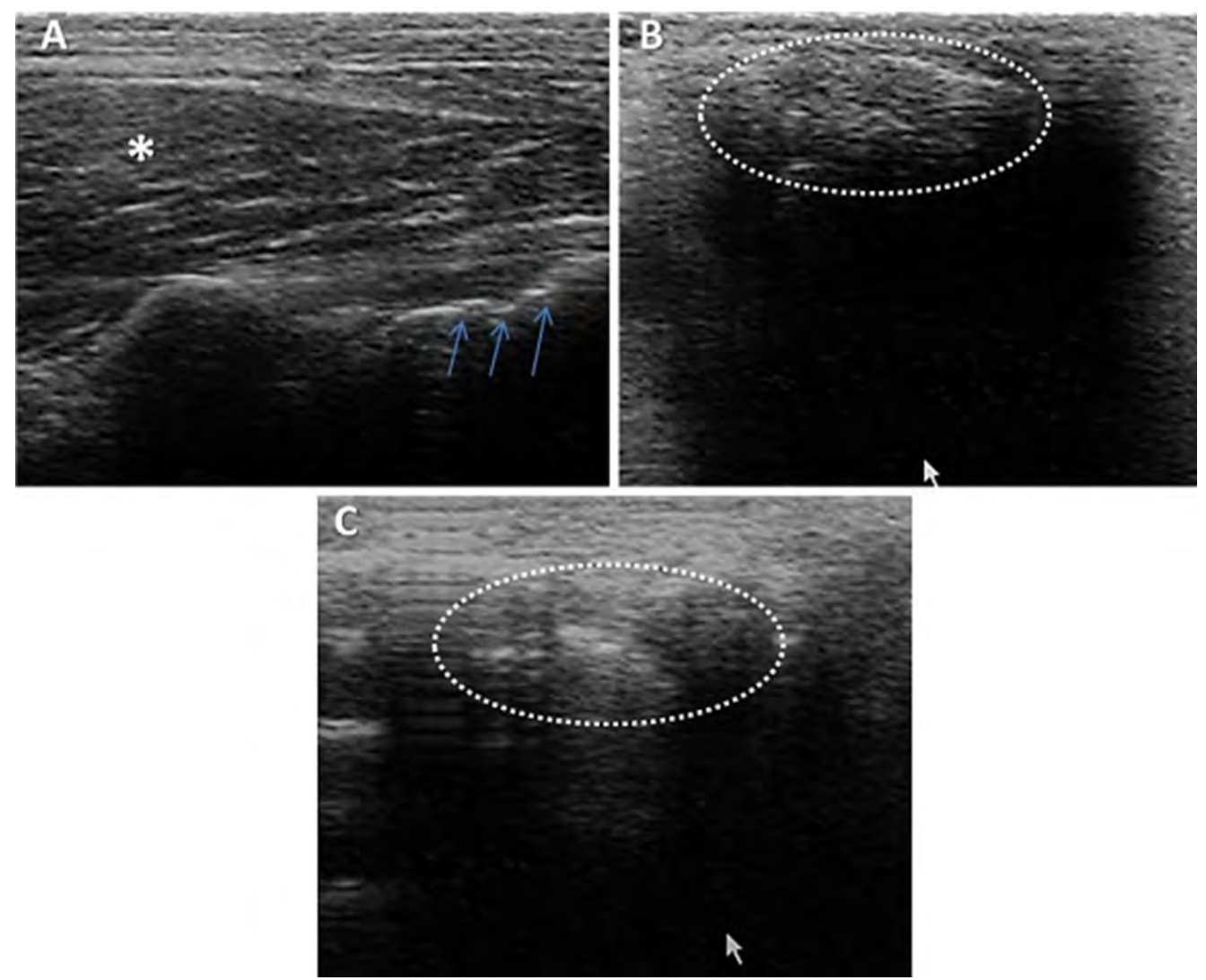

Figure 2. Ultrasound image of joints of goat native to the state of Piauí, positive for CAE. (A) humerus head surface, showing surface irregularity and expossed subchondral bone (arrows) and loss of echogenicity of the sub patellar muscle (*). (B) carpus joint. Observe indistinguishable bone margins and intense sound reflection, with an installed degenerative joint process (dotted circle). (C) tarsal joint joint. Note loss of morphology, with tarsal joint bones indistinguishable from one another, loss of joint space and probable pseudoartrose (dotted circle).

\section{DISCUSSION}

The literature establishes measurements of the joints of animals affected by various degrees of arthritis, where absolute values equal or less than $5.5 \mathrm{~cm}$ would indicate negative arthritis diagnosis, variations between 6.0 and $6.5 \mathrm{~cm}$ would be considered suspect and variations equal or greater to $7.0 \mathrm{~cm}$ would be a positive diagnosis $[16,20]$. In our assessments, this description corroborated with our results, as $100 \%$ of our animals positive by the IDGA exam presented joint clinical index between 6.6 and $7.4 \mathrm{~cm}$.

The joint clinical index is only an absolute form for the current clinical occurrence of arthritis [10,23]. The joint inflammations were caused by other diseases, such as those derived from bacteria of the Micoplasma genus can suggest similar semiological aspects and can present positive results to the joint clinical index [22]. In spite of this, in our observations the JCI test was sustained by the diagnostic examination using the IDGA method, a standard test to verify anti-CAEV antibodies [7], and widely accepted in routine diagnostic medicine, both the United States and Europe [17].

From the anatomical point of view, the ultrasound assessment of the joints of the normal animals showed a morphological pattern as observed in dogs [3], horses [19] and humans [24]. Visualization by ultrasound of the patella-humerus joint was limited to the cranial, lateral and caudal aspects of the joint because this access showed all the clinically relevant structures [15]. The access to the medial side of the joint was not possible because of the sound interference triggered by the interposition of the pectoral muscles [12].

The anatomical ultrasound aspects described for the patella-humerus joint are compatible with descriptions in dogs [27], when they described for these animals that the humerus head subchondral bone was visible as a convex hyperechoic line, associated with a strong acoustic shadow, while the cartilage was an anechoic layer of uniform thickness with a superficial hyperechoic interface. Similarly, the supraspinatus 
muscle was observed in proximity to the sub patella, separated by a hyperechogenic tendon margin. In addition, the muscular ventre of the minor supraspinatus muscle was also identified adjacent to the head of the deltoid muscle [25].

The loss of echogenicity, surface erosion and exposed subchondral bone observed in the goats infected with CAEV were also reported in dogs [27] with patella-humerus osteochondrosis, by the presence of a cartilage flap seen radiographically, or even as cracks, characterized by a hyperechoic line parallel to the subchondral defect in the ultrasound examination. Further sustaining our findings, considered the presence of osteochondrosis in dogs [2], because of the presence of radiolucent areas, irregularities or flattening in the caudal aspect of the humerus head, seen in radiographic images. This same author reported that for concomitant observation of free mineralized flaps in the joint, other diagnostic tools should be used in addition to radiographs.

The normal anatomic aspect of the carpal and tarsal joints observed in the present research was also observed in dogs with osteoarthritis [9]. Indeed, both the normal joint aspects and pathological conditions are well consolidated and described in the literature $[1,6]$, and an infinity of medical and surgical treatments used on human beings has been extrapolated for treatment of acute lesions or chronic degenerative diseases of variable seriousness in domestic animals.

Anatomically, the acoustic window selected for ultrasound assessment enabled the definition of the carpal structures in the goats studied. Studies in normal joints of dogs using resonance also adopted the dorsal access as window for the anatomical description of the referred joint, in addition to accessory structures such as the radioulnar disk joint, palmar fiber cartilage, radioulnar ligament, radial and ulnar collateral ligaments, palmar-ulnar-carpal ligaments, and the transversal intercarpal ligaments [18].

The lesions observed in the ultrasound examination showed various degrees of osteoarthritis, with the presence of sound hyperreflection, hyperechogenic areas, cartilage lesions with the erosion of the subchondral bone and loss of anatomic limits. The same characteristics were described for the metacarpal phalagean and metatarsal phalangean joints of dogs submitted to routine radiographic examination [9]. Allied to this, ultrasound examination improves the assessments to diagnose severe osteoarthritis of the proximal and distal intertarsal and metatarsal regions of horses describing the presence of cartilage thickening and osteochondrosis lesions and abnormally diluted cartilage, which are the base of our results regarding the description of the lesions observed in the present experiment [26].

Studies carried in horses demonstrated by radiographic examination the presence of periarticular osteophytes in degenerative tarsal joint disease, although the authors did not attribute these findings specifically to the degree of clinical affection [4]. It is important to emphasize that in our findings the use of the ultrasound examination was capable of obtaining a similar level of precision in identifying the lesions described by these authors who used radiographic assessment.

Add to this the possibility of deepening knowledge on the interpretive analysis of the normal anatomy of joints in domestic and production animals by ultrasonography, such as the goat, helping in clinical diagnostic procedures, a practice already observed in horse medicine [21], when by ultrasonography exam they guided the removal of fragments of the second carpal bone in an arthrotomy procedure.

\section{CONCLUSION}

The ultrasound examination of the joints of normal goats and goats infected with the caprine arthritis encephalitis virus allowed comparative description of the normal anatomy, the evolution of the joint lesions and adjacent soft tissues, generating valuable clinical and surgical information. It is a valuable complimentary examination, because it assesses the degree of the lesion of the joints affected by the virus. Furthermore, establishing a complimentary ultrasonography pattern that may suggest a diagnostic of CAEV in the field is fundamentally important to maximize control measures and reduce losses to sheep and goat rearing.

\section{MANUFACTURERS}

${ }^{1}$ Biovetech - Indústria e Comércio de Produtos Biotecnológicos Ltda. - ME. Recife, PE, Brazil.

${ }^{2}$ SonoSite Inc. Bothell, WA, USA.

Ethical approval. The protocols used in the present study were approved by the committee of ethics and animal experimentation at the Federal University of Piauí ( $\left.N^{\circ} 10 / 09\right)$.

Declaration of interest. Authors report no conflict of interest. The authors are solely responsible for the content and writing of the paper. 


\section{REFERENCES}

1 Allan G.S. 2007. Radiographic signs of joint disease in dogs and cats. In: Thrall D.E. (Ed). Textbook of Veterinary Diagnostic Radiology. 5th edn. St. Louis: Saunders Elsevier, pp.319-348.

2 Bardet J.F. 2002. Shoulder diseases in dogs. Veterinary Medicine. 97: 909-918.

3 Bertolini G., Furlanello T. \& Caldin M. 2003. Preliminary experiences and clinical applications of multislice-CT in small animal practice. In: Proceedings of the Autumn Meeting. European Association of Veterinary Diagnostic Imaging (Cambridge, UK). 23p.

4 Björnsdóttir S., Axelsson M., Eksell P., Sigurdsson H. \& Jcarlsten J. 2000. Radiographic and clinical survey of degenerative joint disease in the distal tarsal joints in Icelandic horses. Equine Veterinary Journal. 32: 268-272.

5 Blacklaws B.A., Berriatua E., Torsteinsdottir S., Watt N.J., Andres D., Klein D. \& Harkiss G.D. 2004. Transmission of small ruminant lentiviruses. Veterinary Microbiology. 101: 199-208.

6 Breuer H.E. 2003. Treatment of osteoarthrosis of the metacarpophalangeal joint by excision arthroplasty in a dog. Kleintierpraxis. 48: 91-95.

7 Crawford T.B. \& Adams D.S. 1981. Caprine arthritis-encephalitis: clinical features and presence of antibody in selected goat population. Journal of the American Veterinary Medical Association. 178: 713-719.

8 Denoix J.M. 1996. Ultrasonographic examination in the diagnosis of joint disease. In: McIlwraith C.W. \& Trotter G.W. (Eds). Joint disease in the horse. Philadelphia: Saunders Elsevier, pp.165-202.

9 Franklin S.P., Park R.D. \& Egger E.L. 2009. Metacarpophalangeal and metatarsophalangeal osteoarthritis in 49 dogs. Journal of the American Animal Hospital Association. 45: 112-117.

10 Garcia M., Galhardo M., Araújo W.P., D’Angelino J.L., Bastos P.A.S. \& Rossini A.J. 1992. Caprine ArthritisEncephalitis (CAE). Occurrence of positive sera in goats raised in Brazil. Tropical Animal Health Production. 24: 64-64.

11 Gregory L., Lara M.C.C.S.H., Villalobos E.M.C., Hasegawa M.Y., Castro R.S., Rodrigues J.N.M., Araujo J., Keller L.W. \& Durigon E.L. 2009. Detecção do vírus da artrite encefalite caprina em amostras de leite de cabras pela reação em cadeia da polimerase (PCR) e NESTED-PCR. ARS Veterinaria. 25: 142-146.

12 Hoskinson J.J. \& Tucker R.L. 2001. Diagnostic imaging of lameness in small animals. Veterinary Clinics of North America: Small Animal Practice. 31: 165-179.

13 Lechner F., Schütte A., Von-Bodungen U., Bertoni G., Pfister H., Jungi T.W. \& Peterhans E. 1999. Inducible nitric oxide synthase is expressed in joints of goats in the late stage of infection with caprine arthritis encephalitis virus. Clinical Experimental Immunology. 117: 70-75.

14 Lechner F., Vogt H.R., Seow H.F., Von-Bodungen U., Bertoni G., Zurbriggen A. \& Peterhans E. 1996. Expression of TNF alpha in arthritis caused by caprine arthritis encephalitis virus. Veterinary Immunology Immunopathology. 54: 281-289.

15 Long C.D. \& Nylan T. Ultrasonographic evaluation of the canine shoulder. Veterinary Radiology Ultrasound. 40: 372-379.

16 Monicat F. 1987. Caprine arthritis-encephalitis in France. Veterinary Record. 120: 478-479.

17 Narayan O. \& Cork L.C. 1990. Caprine arthritis-encephalitis virus. In: Dinter Z. \& Morein B. (Eds). Virus infections of ruminants. The Netherlands: Elsevier Science, pp.441-452.

18 Norderg C.C. \& Johnson K.A. 1998. Magnetic resonance imaging of normal canine carpal ligaments. Veterinary Radiology Ultrasound. 39: 128-136.

19 Park R.D., Nelson T.R. \& Hoopes P.J. 1987. Magnetic resonance imaging of the normal equine digit and metacarpophalangeal joint. Veterinary Radiology Ultrasound. 28: 105-116.

20 Perrin G. \& Polack B. 1987. L'arthrite encéphalite caprine (CAE). Bulletin de L'Académie Vétérinaire de France. 60: 125-136.

21 Piccot-Crezollet C. \& Cauvin E.R. 2005. Treatment of a second carpal bone fracture by removal under ultrasonographic guidance in a horse. Veterinary Surgery. 34: 662-667.

22 Ramalho E.J. 2000. Artrite-encefalite caprina - CAE: prevalência de anticorpos séricos em caprinos criados no Estado da Bahia. 109f. São Paulo, SP. Tese de Doutorado em Clínica Veterinária, Faculdade de Medicina Veterinária e Zootecnia, Universidade de São Paulo. 
23 Rossini A.J., Garcia M., Araújo W.P. \& Iwasaki M. 1986. Micoplasmose caprina. Relato de dois casos ocorridos no Estado de São Paulo. In: Anais da Semana Medicina Veterinária da Faculdade de Medicina Veterinária e Zootecnia da Universidade de São Paulo (São Paulo, Brasil). p.70.

24 Salaffi F., Filippucci E., Carotti M., Naredo E., Meenagh G., Ciapetti A., Savic V. \& Grassi W. 2008. Inter-observer agreement of standard joint counts in early rheumatoid arthritis: a comparison with grey scale ultrasonography-a preliminary study. Rheumatology. 47: 54-58.

25 Siems J.J., Breur G.J., Blevins W.E. \& Cornell K.K. 1998. Use of two-dimensional realtime ultrasonography for diagnosing contracture and strain of the infraspinatus muscle in a dog. Journal of American Veterinary Medical Association. 212: 77-80.

26 Tomlinson J.E., Redding W.R. \& Sage A. 2000. Ultrasonographic evaluation of tarsocrural joint cartilage in normal adult horses. Veterinary Radiology Ultrasound. 41: 457-460.

27 Vandevelde B., Van Ryssen., Saunders J.H., Kramer M. \& Van Bree H. 2006. Comparison of the ultrasonographic appearance of osteochondrosislesions in the canine shoulder with radiography, arthrography, and arthroscopy. Veterinary Radiology Ultrasound. 47: 174-184. 